\title{
Comunicação organizacional e mídias móveis: possibilidades e desafios
}

\section{Organizational Communication and Mobile Media: possibilities and challenges}

Camila Maciel Campolina Alves Mantovani ${ }^{1}$

Maria Aparecida Moura ${ }^{2}$

Resumo: O artigo busca refletir sobre as possibilidades e os desafios das interações entre as organizações e seus públicos de interesse, em especial os clientes finais, diante da diversidade de mídias e mediações (com destaque para as mídias móveis). Ao ampliar os pontos de contato entre os sujeitos e as marcas, a presença e o uso quase constante das mídias digitais acabam por demandar da comunicação organizacional a proposição de novas estratégias de abordagem e relacionamento com os públicos de interesse. Aqui serão apresentadas e discutidas algumas iniciativas à luz das reflexões em torno da midiatização e das teorias da mobilidade no âmbito da comunicação.

Palavras-chave: comunicação organizacional; midiatização; mobilidade; consumo.

Abstract: The article seeks to reflect on how the variety of media and mediations (especially mobile media) brought new possibilities for interaction between organizations and their stakeholders, in particular the end customers. By extending the touchpoints between the subjects and the brands, the presence and the almost constant use of digital media end up demanding that organizational communication starts thinking and proposing new strategies to approach and relate with stakeholders. Some initiatives will be presented and discussed here and based upon the reflections brought by mediatization e mobility theories.

Keywords: Organizational communication, mediatization, mobility, consume.

1 Universidade Federal de Minas Gerais. Belo Horizonte, MG, Brasil. E-mail: camilamm@gmail.com

2 Universidade Federal de Minas Gerais. Belo Horizonte, MG, Brasil. E-mail: cidamoura@gmail.com 


\section{Introdução}

Nos últimos 20 anos, as tecnologias eletrônicas e digitais modificaram a maneira como nos comunicamos. A discussão em torno da centralidade da esfera midiática na vida cotidiana e nas relações sociais vem sendo desenvolvida a partir da análise de suas implicações econômicas, políticas, culturais. Os estudos sobre globalização, mundialização da cultura e dinamização dos fluxos informacionais têm como foco a percepção da crescente penetração das mídias nas mais diversas camadas da vida social, desempenhando papel importante em relação a mudanças nas formas de interação social.

A comunicação midiática, a partir do desenvolvimento das tecnologias e das alterações em seus usos, tem se modificado. Alguns autores chegam a definir esse processo como midiatização das sociedades (FAUSTO NETO, 2006, 2008, 2010; SODRÉ, 2002). No entanto, para além de um determinismo tecnológico presente na crítica em relação aos estudos de midiatização, faz-se necessária a compreensão das lógicas midiáticas inseridas nas práticas sociais e nos processos de sociabilidade contemporâneos.

Silverstone, ao se fazer a pergunta "por que estudar a mídia?", nos oferece como resposta o

[...] reconhecimento de que nossa mídia é onipresente, diária, uma dimensão essencial de nossa experiência contemporânea. É impossível escapar à presença, à representação da mídia. Passamos a depender da mídia, tanto impressa como eletrônica, para fins de entretenimento e informação, de conforto e segurança, para ver algum sentido nas continuidades da experiência e, também, de quando em quando, para as intensidades da experiência (SILVERSTONE, 2002, p. 12).

Diante desse cenário, destacamos, em nossa discussão, outro elemento importante a compor a paisagem comunicacional contemporânea: a 
mobilidade. Nesse sentido, se antes havia tempo e lugar para atividades como assistir à TV, jogar, enviar e-mail, pagar contas ou navegar em um website, hoje, com as mídias móveis, os sujeitos podem escolher e acessar diferentes conteúdos sem muitas restrições contextuais para suas interações. ${ }^{3}$

Dentre os aparelhos que ajudam a disseminar a mobilidade infocomunicacional, destacamos os celulares e smartphones. Esses equipamentos, que, além dos serviços de voz, agregam informações em multiformatos e conexão com a internet, estão cada vez mais presentes na paisagem urbana.

Computadores portáteis, tablets, redes wi-fi, sistemas bluetooth, dentre outros, também se tornaram mais difundidos, sendo incorporados ao cotidiano de diversos sujeitos que, de maneira quase compulsória, necessitam manter sua força de trabalho disponível e conectada enquanto estão em movimento e, também, para estabelecer interações relacionadas à sua vida privada.

As trocas comunicacionais em movimento alteraram de forma significativa a maneira como as pessoas se informam, se divertem, trabalham, estudam, consomem e expressam sentimentos. Ao contribuir para a disseminação de novas possibilidades de interação, tanto entre os sujeitos quanto entre eles e os conteúdos, tais mídias acabam por engendrar uma sociedade sempre conectada e disponível para ingressar em processos interativos, atuando como próteses de interação, extensões do corpo humano.

Celulares são tidos como recursos de conexão permanente. O indivíduo se torna sempre disponível. O logo da comunicação móvel é a disponibilidade constante. Seja no meio de Budapeste ou Manhattan, numa fazenda no interior de Minas Gerais ou num hotel em Manaus, a pessoa está sempre ao alcance, pois, como um objeto material, o celular funciona como um ícone do diálogo, de uma conexão tecnoumbilical (GERGEN, 2003,

3 Ressalvando-se aí questões vinculadas à infraestrutura das companhias de telefonia móvel - área de cobertura, qualidade do serviço -, ao próprio equipamento - bateria, memória, funcionalidades - e, principalmente, àquelas de ordem financeira: o Brasil tem um dos serviços de telefonia móvel mais caros do mundo (DANTAS, 2002), somado ao alto preço dos aparelhos, em especial dos smartphones. 
p. 111). É claro que estar sempre ao alcance também significa ser sempre detectável, o que torna o indivíduo mais visível para as corporações dos negócios que farejam informações sobre as pessoas, obrigando os indivíduos a desenvolver estratégias de proteção (SANTAELLA, 2007, p. 238).

Assim como as tecnologias têm motivado novas práticas em diversos campos sociais, no âmbito da comunicação organizacional não seria diferente. A variedade de mídias e mediações (com destaque para as mídias móveis) apresenta novas possibilidades de interação entre as organizações e seus públicos de interesse, especialmente os clientes finais.

Com as possibilidades de produção e circulação de conteúdos a partir da web, novas configurações de interação se materializam e as organizações se deparam, como dito anteriormente, com outras conformações discursivas que vão modificar a dimensão estratégica dos processos comunicativos. Surgem novas características de interlocução, marcadas pela dispersão e fluidez (OLIVEIRA et al., 2012, p. 10).

No que concerne à dimensão do consumo, as possibilidades advindas do uso das mídias móveis, com ênfase nos smartphones, parecem ampliar os pontos de contato entre sujeitos e organizações/marcas. Tal fato tem desafiado a comunicação organizacional a pensar e a criar novas estratégias para se relacionar com o consumidor.

Nesse contexto, destacamos o termo mobile marketing, que, já há algum tempo, vem sendo empregado para caracterizar ações promocionais realizadas por meio dos celulares e/ou smartphones.

Das mensagens SMS aos QR codes e jogos que exploram as potencialidades de geolocalização dos equipamentos de telefonia celular, as estratégias para abordar o consumidor via mídias móveis se multiplicam, demandando uma reflexão acerca das interações geradas a partir de práticas de consumo contemporâneas.

No que se refere especificamente às ações de mobile marketing, vemos que, no contexto brasileiro, elas têm acontecido de maneira bastante diversa. Algumas ações são tímidas; outras, por vezes, revelam-se bastante incisivas, chegando mesmo a provocar certa "irritação" nos 
consumidores. De repente, o telefone toca e lá está uma mensagem com alguma oferta "imperdível”. Em alguns casos, foi o próprio usuário quem "autorizou" o envio da oferta. Porém, não é raro que muitas dessas mensagens cheguem de maneira indesejada ao celular.

As mídias móveis - especialmente os smartphones - apresentam um conjunto de características intrínsecas que os tornam interessantes para as ações de marketing: a portabilidade, a multifuncionalidade, a conectividade e o uso individualizado. Tais elementos, de maneira combinada, geram oportunidades para compra e venda, bem como para criação de um canal de interação entre consumidores e marcas.

Segundo pesquisa divulgada pela Pew Internet ${ }^{4}$ (setembro de 2013) nos Estados Unidos, 63\% dos adultos que possuem telefone celular usam seu aparelho para acessar a internet. Desse número, 34\% dizem acessar a web preferencialmente pelo celular/smartphone. Sendo assim, $21 \%$ dos adultos estadunidenses que possuem telefone móvel navegam pela internet, de preferência, por meio do aparelho móvel.

No Brasil, de acordo com pesquisa realizada pelo Google em parceria com a Ipsos MediaCT entre usuários ${ }^{5}$ que possuem smartphones e acessam a internet por meio do aparelho, $82 \%$ dos entrevistados pesquisaram um produto e/ou serviço através do celular e $30 \%$ já adquiriram um produto e/ou serviço com seus aparelhos.

As potencialidades das mídias móveis, quando postas em números, são bastante expressivas; porém, trata-se apenas de um dos componentes da análise em torno do tema. Essas mídias se inserem em complexo universo de discussões e reflexões acerca da mobilidade. Sendo assim, é preciso que nos detenhamos em conceitos relativos ao tema para que possamos, então, buscar compreender suas implicações no campo do consumo e da comunicação organizacional.

4 Disponível em: http://pewinternet.org/Reports/2013/Cell-Internet/Summary-of-Findings.aspx. 5 A amostra foi composta por mil brasileiros adultos (entre 18 e 64 anos) e usuários de internet que declararam usar smartphones para acessar a web. Segundo relatório, a distribuição está em conformidade com estudo com representatividade nacional e os dados ponderados de acordo com idade, sexo, região, marca do smartphone, frequência de uso da internet no celular e uso de tablet. Disponível em: http://services.google.com/fh/files/misc/omp-2013-br-local.pdf. Acesso em: dez. 2013. 


\section{Mobilidade}

Ao percorrer a trajetória histórica dos meios, percebe-se um movimento dinâmico: da oralidade para a escrita, da escrita para a imprensa, desta para as mídias eletrônicas (o rádio e a televisão), até chegar às tecnologias digitais, que promoveram a desmaterialização e a hibridação dos suportes.

Dos personal computers aos "computadores coletivos" - conectados ao ciberespaço (LEMOS, 2005) - no século XXI, chega o momento das tecnologias móveis exemplificadas nas redes wi-fi, nos smartphones, tablets e notebooks. A informação, que já transitava pela rede, percorrendo distâncias até chegar aos sujeitos que se localizam em pontos específicos, passa agora a se mover junto a esses sujeitos.

Essa situação de mobilidade generalizada, em que corpos, informações, produtos e capital põem-se em circulação, insere-se contemporaneamente no contexto que alguns teóricos do campo das ciências sociais definiram como o paradigma da mobilidade (URRY, 2007). Tal paradigma extrapola a questão comunicacional e informacional e situa a ideia do movimento como peça-chave para melhor compreensão dos fenômenos sociais contemporâneos. Dentre as diversas acepções desse paradigma, interessa-nos destacar, neste contexto de problematização, o aspecto referente à mobilidade por fluxos informacionais.

Segundo Urry (2007), o desenvolvimento das tecnologias de informação e comunicação proporcionou o que se convencionou chamar de mobilidade produtiva. Nesse panorama, além de atividades típicas do estar em movimento, o autor destaca o fato de que as tecnologias móveis permitiram a realização de várias outras atividades, principalmente aquelas ligadas ao trabalho e às interações pessoais.

As potencialidades fornecidas pelas tecnologias móveis para efetuar a microcoordenação da vida cotidiana também já foram discutidas por

6 A partir do desenvolvimento teórico e das crescentes análises empíricas a respeito do fenômeno da mobilidade nos mais distintos aspectos da vida, surge, na perspectiva do autor, uma forma diferenciada de se pensar as características das relações econômicas, sociais e políticas que apontariam para uma "virada da mobilidade" (mobility turn) nas ciências sociais (URRY, 2007). 
pesquisadores como Ling (2004) e Katz e Aakhus (2002) e são frequentemente usadas nas campanhas publicitárias em torno dos dispositivos móveis. Já que o ritmo da vida moderna impõe uma rotina acelerada aos sujeitos, para uma parcela da população adulta, urbana e economicamente ativa, os dispositivos móveis ampliaram a possibilidade de coordenar à distância atividades rotineiras.

Nesse sentido, o uso das mídias móveis corresponde a um estilo de vida. Para Elliott e Urry,

A vida "em movimento" é o tipo de vida em que a capacidade de estar em "outro lugar" num momento diferente dos outros é central. E-mail, mensagens SMS, dispositivos MP3, gravadores de DVD portáteis, serviços telefônicos na internet e assim por diante permitem às pessoas escapar das limitações de tradições preexistentes ou de formas tradicionais de vida cultural sob padrões e práticas de vida mais fluidos. Essa vida em movimento demanda flexibilidade, adaptabilidade, reflexividade - estar pronto para o inesperado, para abraçar a novidade, já que até mesmo os outros sujeitos significativos estão fazendo coisas diferentes e em momentos diferentes. As experiências das pessoas são dessincronizadas entre si, de modo que os sistemas e os sujeitos têm que estar disponíveis just in time (ELLIOTT; URRY, 2010, p. 4, tradução nossa).

Esse movimento narrado pelos autores e atribuído a uma determinada elite global foi caracterizado por Bauman (1999) no paradigma do turista, tendo como contraponto o do vagabundo. O turista é aquele que se move por escolha, que pode ser efeito da "sedução operada pela mítica do movimento" ou estar baseada em uma racionalidade estratégica, tendo em vista as "circunstâncias" que se apresentam.

Apesar de as tecnologias móveis conferirem um caráter "novidadeiro" à mobilidade, a relação humana com o movimento é ancestral - tanto que o próprio conceito de nomadismo, adotado contemporaneamente para dar conta dos processos que se configuram nesse contexto, tem sua origem na prática dos povos nômades. Nesse processo de locomoção pelo espaço, esses povos usavam os recursos oferecidos pelo ambiente até que se esgotassem, iniciando, assim, um novo deslocamento em busca de outra região que propiciasse condições de sobrevivência. 
Maffesoli (2001), no texto Sobre o nomadismo, chama atenção para o fato de que esse desejo ancestral de movimento vem se manifestando, de diferentes maneiras, ao longo da evolução humana. Para o autor, o termo "errância" foi domesticado sob o termo "mobilidade", referindo-se, portanto, aos constantes movimentos dos sujeitos contemporâneos, que seriam: migrações diárias (trabalho, consumo), migrações sazonais (turismos, viagens) e, por fim, a mobilidade social, provocada pelas disparidades econômicas.

Segundo Maffesoli (2001), esses deslocamentos são a forma de o homem moderno reviver a "aventura" dos tempos nômades. Esse desejo, que subjaz ao desejo de errância, pode sim, na perspectiva do autor, ser satisfeito pelas experiências proporcionadas pelas tecnologias da mobilidade, incluindo-se aí não somente as tecnologias de comunicação e informação, mas também as de transporte.

O minitel, o avião, a "internet" e as diferentes redes eletrônicas, a televisão e as autoestradas da informação, tudo isso, para o bem ou para o mal, permite viver, em tempo real e sobretudo coletivamente, experiências culturais, científicas, sexuais e religiosas que são, justamente, o próprio da aventura existencial. As potencialidades do ciberespaço estão longe de se esgotar, mas já testemunham o enriquecimento cultural que está sempre ligado à mobilidade, à circulação, quer sejam as do espírito, dos devaneios e até das fantasias, que tudo não deixa de induzir (MAFFESOLI, 2001, p. 30).

No trecho anterior, Maffesoli (2001) ainda se referia ao ciberespaço para dizer da mobilidade por fluxos informacionais. Atualmente, as tecnologias móveis potencializaram esse tipo de movimento, na medida em que ampliaram os pontos de conexão na rede. Porém, a mobilidade contemporânea instaura uma contradição, pois ao mesmo tempo que as tecnologias permitem o movimento, exercem uma ação de regulação e controle. Estamos livres para nos mover, porém nosso movimento via tecnologias é registrado, mapeado, monitorado.

Para Manovich (2006), esse seria um dos pontos principais da noção de espaço aumentado (augmented space): a relação tênue entre 
vigilância/controle e assistência/adição de informações. Na perspectiva do autor, quando o espaço físico torna-se um espaço informacional, os sujeitos passam a vivenciar uma dupla situação: tem-se a possibilidade do uso dos dispositivos (móveis ou não), que extraem informações do espaço - contribuindo para ações de vigilância, rastreamento e monitoramento -, assim como de ampliar a percepção do espaço a partir da inserção de camadas de informação, que podem ser acionadas por meio de dispositivos diversos.

Bruno (2013) reforça essa ideia ao pontuar que a constante presença do sujeito na rede, além de notadamente lhe permitir articular ações de natureza diversa - desde aquelas ligadas à exposição do "eu" a ações coletivas de cunho político -, também o torna mais vulnerável ao monitoramento.

[...] ao mesmo tempo que as possibilidades de expressão e ação individual e coletiva são potencializadas, dispositivos de monitoramento e captura de dados dos usuários se tornam cada vez mais presentes nestas mesmas plataformas e redes, tendendo a integrar seus próprios parâmetros de funcionamento e eficiência. Sob o fluxo visível das trocas e conversações sociais, constitui-se um imenso, distribuído e polivalente sistema de rastreamento e categorização de dados pessoais que, por sua vez, alimenta estratégias de publicidade, segurança, desenvolvimento de serviços e aplicativos, dentro e fora destas plataformas (BRUNO, 2013, p. 9).

Vale retomar, neste ponto, a fala de Bauman (2001) quando chama atenção para o fato de que, no "estágio sólido da era moderna", os hábitos nômades eram malvistos e, nesse contexto, ser cidadão significava dispor de lugar fixo, assentar-se no espaço (trabalho, família, posição social). Já nos dias atuais, ainda que os andarilhos e sem-teto continuem malvistos, há o retorno do nomadismo no formato das elites globais extraterritoriais. "A elite global contemporânea é formada pelos senhores ausentes", pontua.

Ser moderno passou a significar, como significa hoje em dia, ser incapaz de parar e ainda menos de ficar parado. Movemo-nos e continuaremos a nos mover não tanto pelo "adiamento da satisfação", como sugeriu 
Max Weber, mas por causa da impossibilidade de atingir a satisfação: o horizonte da satisfação, a linha de chegada do esforço e o momento da autocongratulação tranquila movem-se rápido demais (BAUMAN, 2001, p. 37).

Assim, na visão de Bauman (2008), a mobilidade dos sujeitos contemporâneos se assemelha menos à dos viajantes ou dos migrantes - que tinham como objetivo chegar a algum lugar - e mais à dos errantes, que têm no "estar em movimento" o seu objetivo principal.

Ao movimento, soma-se a questão do consumo, que, na perspectiva do autor, torna-se a principal exigência contemporânea. "A maneira como a sociedade atual molda seus membros é ditada primeiro e acima de tudo pelo dever de desempenhar o papel de consumidor" (BAUMAN, 1999, p. 88).

Com essa afirmação, Bauman (1999) deseja destacar a ênfase atual no consumo e, nesse sentido, a ideia do movimento é extremamente pertinente, pois põe o sujeito sempre em busca de alguma coisa. Além disso, essa busca incessante, ainda que provoque certo desconforto, fala de uma nova forma de estar neste mundo, de participar e de se integrar socialmente. Ter novos desejos a serem satisfeitos e sempre buscar algo são ações representativas da ideia de que se está vivo. Nas palavras do autor: "a imobilidade, ao fim, significa a morte".

Diante disso, é preciso dar início a uma reflexão em torno de como as apropriações cotidianas das tecnologias, em especial as mídias móveis, estão incidindo não apenas sobre as interações entre os sujeitos e a sociedade, mas também nos deter em contextos específicos, como aqueles que remetem às organizações e a seus públicos de interesse.

\section{Midiatização e comunicação organizacional}

Em um mundo pleno de estímulos e necessidades a serem criadas e satisfeitas continuamente pelo mercado, a comunicação organizacional, voltada para a interlocução entre clientes e empresas, desempenha importante papel ao atuar nas dimensões simbólicas do consumo. No que 
se refere à interação entre consumidores e marcas, as mídias móveis têm se tornado, cada vez mais, um importante mediador.

Nesse sentido, tais tecnologias passam a fazer parte dos estilos de vida dos sujeitos, que, por sua vez, começam a guiar o desenvolvimento dos equipamentos não apenas em termos de design, mas principalmente em relação às funcionalidades. Toda a infraestrutura que se mobiliza para entregar o conteúdo/serviço volta suas atenções ao sujeito.

Sendo assim, a comunicação estratégica no âmbito das mídias móveis vai muito além do desenvolvimento de campanhas, mas se refere à consolidação da presença da organização no ambiente móvel. Para tanto, várias ações, desde a criação de um aplicativo ou site responsivo até a adoção de nova postura (dialógica) em relação ao consumidor/cliente, representam passos importantes.

Uma reflexão inicial acerca das potencialidades e desafios da comunicação - via tecnologias móveis - entre uma organização e seus públicos de interesse pode se dar a partir da análise de estratégias corriqueiras de abordagem do consumidor, como o envio de um e-mail promocional ou um SMS. Geralmente, no conteúdo de tais mensagens, há sempre a inserção de um link para o site da marca ou mesmo o telefone da empresa. Assim, se aquela oferta despertar a atenção do consumidor, ele buscará formas de entrar em contato com a empresa, seja por meio do clique no link - para obter mais informações ou dar início a um processo de compra -, seja através do número de telefone.

Porém, no primeiro caso, muitas vezes ele se frustra porque o site não foi pensado para o ambiente móvel, dificultando ou mesmo impossibilitando a navegação. Algo ainda mais comum costuma acontecer: o telefone para contato está em formato de imagem e não permite ao usuário clicar e iniciar, dali mesmo, uma ligação/interação. Portanto, nesse contexto, é preciso ter em conta que, assim como acontece na web, nas mídias móveis, o meio em que se anuncia é também o lugar onde se pode iniciar (e até mesmo concluir) o processo de aquisição de determinado serviço ou produto. 
É importante destacar que, no caso dos celulares, a presença ou a aceitação da comunicação estratégica não aconteceu (e ainda não acontece) de forma tranquila. Muitas pessoas não se sentem à vontade para receber, em seus aparelhos, mensagens de cunho publicitário, por exemplo. Pesquisas apontam que o uso "indiscriminado" do SMS como ferramenta para veicular promoções e ofertas causa certo desconforto e até rejeição a essa forma de comunicação (KATZ; AAKHUS, 2002; LING, 2008).

Essa percepção pode ser explicada pelo fato de que as interações via SMS (assim como as ligações) fazem parte de um universo de conexões que se estabelecem, na maioria das vezes, entre os laços fortes da rede dos sujeitos. É um território de interações pessoais. Assim, quando toca o alerta de recebimento de mensagem, há uma grande expectativa em torno da importância daquela mensagem para o sujeito que a recebe. Portanto, há frustração quando o conteúdo é uma "imperdível" oferta ou um lembrete de vencimento de conta.

Sendo assim, antes da consolidação da internet nos celulares e, por conseguinte, da presença de fluxos informacionais e comunicacionais diversos nos aparelhos, a comunicação entre organizações e clientes finais acontecia a partir da lógica do "marketing de permissão". Era preciso autorização do usuário para envio de determinada oferta via SMS ou MMS. No entanto, para minimizar os efeitos negativos da rejeição, era necessário também (e ainda é) atentar-se para a individualização da oferta. Quanto mais personalizadas, maiores as chances de essas mensagens serem percebidas como serviços de informação de valor, em oposição a incômodas e disruptivas mensagens "nada a ver" (BARNES; SCORNAVACCA, 2004).

Diante do potencial dessa mídia em estabelecer um fluxo bidirecional de comunicação, muitas marcas adotam, como estratégia de individualização da oferta, um discurso que simula um diálogo "um para um" entre a organização e o consumidor. Porém, tal interação pode se mostrar bastante frágil e inócua, já que muitas vezes, apesar da roupagem individualizada, configura-se uma comunicação um para todos. 
Outro elemento característico das mídias móveis e que se apresenta como fator importante para a comunicação entre organizações e consumidores é a relação dessas tecnologias com o lugar. Nesse caso, os serviços de geolocalização permitem a geração de mensagens/interações sensíveis ao ambiente onde se encontra o sujeito.

Muitas vezes, devido a restrições técnicas e outras ligadas à preservação da privacidade, é preciso que o usuário insira determinadas coordenadas (a partir de número - large account - enviado via SMS, QR code, ativação do bluetooth) no sistema para, então, acessar ofertas ou serviços pensados para aquele contexto.

Sobre esse último aspecto, cabe ressaltar que não só as marcas se valem desse tipo de funcionalidade, mas também os consumidores podem se beneficiar. Poder acessar informações sobre produtos e serviços dentro do ponto de venda, por exemplo, é algo que possibilita ao consumidor realizar uma compra mais consciente. As tecnologias móveis, nesses contextos, são usadas para consultar informações detalhadas sobre produtos, preços e ofertas, interferindo no processo de negociação.

Outro ponto importante a ser destacado em relação à comunicação estratégica em mídias móveis refere-se à capacidade de determinado anúncio ou campanha ser retransmitido pelo consumidor à sua rede de contatos. Nomeado de marketing viral ou buzz marketing, o "boca a boca", via tecnologias de informação e comunicação, ganha nova dimensão.

Em grande parte dos fluxos informacionais que transitam e são acessados pela internet - seja via computador pessoal, smartphones e/ou tablets -, percebe-se a lógica da intervenção e da manipulação da mensagem. Os sujeitos são estimulados a dar a sua contribuição ao processo comunicacional por meio da produção e/ou reciclagem de conteúdos de natureza diversa, promovendo sua disseminação. Tal comportamento, no âmbito do marketing, por exemplo, desperta especial interesse pelo fato de que uma mensagem enviada por alguém com quem se mantém uma relação próxima tem mais chances de ser bem recebida 
do que aquela enviada por terceiros - nesse caso, anunciantes/empresas (BAUER et al., 2005).

Do ponto de vista dos consumidores, no que concerne ao uso das mídias móveis para estabelecer trocas comunicacionais voltadas à aquisição de serviços/produtos e/ou interação com as organizações, é preciso destacar a ampliação de sua capacidade de ação.

A presença das marcas/organizações nas redes de interação por onde circula grande parte dos fluxos informacionais contemporâneos, apesar de invasiva, opera dentro da lógica de dupla via destacada por Bruno (2013): o ver e ser visto.

Sendo assim, ao mesmo tempo que a presença das organizações nesses circuitos permite obter informações preciosas em relação a comportamentos, hábitos e preferências do consumidor, elas também se expõem e são alvo de críticas e cobranças dos consumidores quando estes não se sentem satisfeitos com os serviços/produtos oferecidos/adquiridos.

Na sociedade de ambiência midiatizada, a proposta da instituição pode ser modificada pelos sujeitos. A emergência de novos espaços de interação, especialmente na internet, amplia as possibilidades de resposta e a interpretação desses sujeitos que possuem condições de construir seus próprios espaços de atuação e, dessa forma, colocar em debate questões de seu interesse (BARICHELLO, 2008, p. 244).

Nesse sentido, podemos afirmar que tais ações se inserem em contexto amplo da gestão dos relacionamentos da organização com os atores sociais. Não se trata apenas da promoção de uma oferta/serviço, mas da complexa produção de sentidos decorrente da relação entre organização e sociedade.

\section{Considerações finais}

Abordar e problematizar as relações entre públicos e organizações implica refletir sobre a perspectiva da midiatização junto aos estudos da comunicação organizacional. As organizações estão cada vez mais "sensíveis” ao comportamento do público final - e vão até ele a partir de 
técnicas diversas. Muitas pesquisas são feitas com o intuito de empoderar as indústrias e os mercados. Sendo assim, seu potencial reflexivo é arrefecido pelas diretrizes de desenvolvimento dos produtos/serviços e pela lógica do mercado/capital. Ou seja, não se desenvolve um olhar crítico para esses usos e consumos.

Nesse sentido, é preciso perguntar algo sobre as relações ali postas sob o ponto de vista cultural, econômico, político, social. Que caminhos têm sido trilhados pelos processos de comunicação organizacional? Que pistas eles nos trazem sobre formas emergentes de interação e relacionamento entre públicos e organização?

Se, por um lado, as discussões em torno da midiatização, com destaque para as mídias móveis, levantam importantes questões sobre como o uso de determinadas tecnologias desfoca, mina ou mesmo transforma as noções de público e privado e a noção de lugar, por outro lado, críticos apontam para o fato de que as mesmas têm sido unicamente exploradas sob o viés da comercialização e do consumo.

Há ainda questões importantes sobre vigilância e controle, que se apresentam de formas por vezes bem-intencionadas - conhecer mais o consumidor, apresentar a melhor oferta, estreitar a comunicação entre organizações e públicos de interesse -, mas que também se prestam a interesses estratégicos ligados a grandes corporações ou até mesmo a governos.

A análise de fenômenos baseados na interação entre sujeitos e organizações, tendo em vista a comunicação móvel em rede - e as possibilidades que ela oferece para a troca de informações, a publicação de opiniões e a criação de novos canais de interação -, faz-se essencial ao entendimento das organizações e de seus processos comunicacionais no século XXI. 


\section{Referências}

BARICHELLO, E. M. M. R. Apontamentos em torno da visibilidade e da lógica de legitimação das instituições na sociedade midiatizada. In: DUARTE, Elizabeth Bastos; CASTRO, Maria Lilia Dias. (Orgs.). Em torno das mídias: práticas e ambiências. Porto Alegre: Sulina, 2008.

BARNES, S. J.; SCORNAVACCA, E. Mobile marketing: the role of permission and acceptance. International Journal of Mobile Communications, v. 2, n. 2, p. 128-139, 2004. BAUER, H. H.; BARNES, S. J.; REICHARDT, T.; NEUMANN, M. M. Driving consumer acceptance of mobile marketing: a theoretical framework and empirical study. Journal of Electronic Commerce Research, v. 6, n. 3, p. 181-192, 2005.

BAUMAN, Z. A sociedade individualizada: vidas contadas e histórias vividas. Rio de Janeiro: Zahar, 2008. 323p.

. Dentro e fora da caixa de ferramentas da sociabilidade. In: Amor líquido: sobre a fragilidade dos laços humanos. Rio de Janeiro: Zahar, 2004. p. 27-45. Globalização: as consequências humanas. Rio de Janeiro: Zahar, 1999. 146p. . Modernidade líquida. Rio de Janeiro: Zahar, 2001.

BRUNO, F. Máquinas de ver, modos de ser: vigilância, tecnologia e subjetividade. Porto Alegre: Sulina, 2013.

DANTAS, M. A lógica do capital-informação: a fragmentação dos monopólios e a monopolização dos fragmentos num mundo de comunicações globais. 2. ed. Rio de Janeiro: Contraponto, 2002. 268p.

ELLIOTT A.; URRY, J. Mobile Lives. Londres: Routledge, 2010.

FAUSTO NETO, A. As bordas da circulação. Revista Alceu, v. 10, n. 20, jan.-jun. 2010. Fragmentos de uma "analítica" da midiatização. Revista MATRIZes, n. 2, abr.

2008 .

Midiatização, prática social-prática de sentido. In: SEMINÁRIO SOBRE MIDIATIZAÇÃO, Rede Prosul. Anais... São Leopoldo: Unisinos, 2006.

KATZ, J. E.; AAKHUS, M. (Orgs.). Perpetual Contact: Mobile Communication, Private Talk, Public Performance. Nova York: Cambridge University Press, 2002.

LEMOS, A. Cibercultura Remix. In: SEMINÁRIO SENTIDOS E PROCESSOS. Anais... São Paulo: Itaú Cultural, ago. 2005. Disponível em: http://www.facom.ufba.br/ ciberpesquisa/andrelemos/cibercultura\%20remix.pdf. Acesso em: 5 fev. 2011.

LING, R. New Tech, New Ties. Cambridge: MIT Press, 2008. 240p.

The Mediation of Ritual Interaction via the Mobile Telephony. In: KATZ, J.

E. (Org.). Handbook of Mobile Communication Studies. Cambridge: MIT Press, 2008. p. $165-176$.

MAFFESOLI, M. Sobre o nomadismo: vagabundagens pós-modernas. Rio de Janeiro: Record, 2001.

MANOVICH, L. The poetics of augmented space. Visual Communication, v. 5 n. 2, p. 219-240, jun. 2006.

OLIVEIRA, I. L.; PAULA M. A.; MARCHIORI, M. Um giro na concepção de estratégias comunicacionais: dimensão relacional. In: ENCONTRO DO FÓRUM 
IBERO-AMERICANO DE ESTRATÉGIAS DE COMUNICAÇÃO. Anais... República Dominicana, 2012. Disponível em: http:/www.uel.br/grupoestudo/gecorp/images/ fisec_2012_painel_texto_final_130712.pdf. Acesso em: 10 nov. 2013.

SANTAELLA, L. Linguagens líquidas na era da mobilidade. São Paulo: Paulus, 2007. SILVERSTONE, R. Por que estudar a mídia? São Paulo: Loyola, 2002.

SODRÉ, M. Antropológica do Espelho. Por uma teoria da comunicação linear e em rede. Petrópolis: Vozes, 2002.

URRY, J. Mobilities. Londres: Routledge, 2007.

\section{Sobre as autoras}

Camila Maciel Campolina Alves Mantovani - Professora do Departamento de Comunicação Social da UFMG. Jornalista (UFMG/2002) e doutora em Ciência da Informação pela Universidade Federal de Minas Gerais (UFMG/2011), com pesquisa sobre Narrativas da mobilidade: comunicação, cultura e produção em espaços informacionais. Seus interesses de estudo abrangem: midiatização, mobilidade informacional, comunicação organizacional, estudos de usabilidade, arquitetura de informação, cultura informacional, estudos de consumo (pesquisa aplicada) em ambientes digitais.

Maria Aparecida Moura - Professora titular da Universidade Federal de Minas Gerais. Graduada em Biblioteconomia pela Universidade Federal de Minas Gerais (1993), mestre em Educação pela Universidade Federal de Minas Gerais (1996), doutora em Comunicação e Semiótica pela Pontifícia Universidade Católica de São Paulo (2002) e pós-doutora em Semiótica Cognitiva e Novas Mídias pela Maison de Sciences de l'Homme (2006-2007). Coordena o Núcleo de Estudos das Mediações e Usos Sociais dos Saberes e Informações em Ambientes Digitais (Nemusad). É professora colaboradora do PPGCOM/UFMG e membro permanente do PPGCI/UFMG. Tem experiência na área de Ciência da Informação, Comunicação e Educação, com ênfase em tecnologias da informação.

Data de submissão: 21/06/2016

Data de aceite: $31 / 01 / 2017$ 